\title{
Satisfaction with travel, ideal commuting, and accessibility to employment
}

\author{
John P. Pritchard \\ Technion Israel Institute of \\ Technology \\ john.pr@campus.technion. \\ ac.il
}

\section{Anne Dorothee Slovic University of São Paulo adslovic@usp.br \\ Mariana Giannotti University of São Paulo mariana.giannotti@usp.br}

\author{
Karst Geurs \\ University of Twente \\ k.t.geurs@utwente.nl \\ Adelaide Nardocci \\ University of São Paulo \\ nardocci@usp.br
}

\author{
Alex Hagen-Zanker \\ University of Surrey \\ a.hagen-zanker@surrey.ac.uk
}

\author{
Diego B. Tomasiello \\ University of São Paulo \\ diegobt86@usp.br \\ Prashant Kumar
University of Surrey
p.kumar@surrey.ac.uk
}

\begin{abstract}
This paper explores relationships between commuting times, job accessibility, and commuting satisfaction based on a large-scale survey applied in the Greater London Area (GLA), the municipality of São Paulo (MSP) and the Dutch Randstad (NLR). Potential accessibility to jobs is estimated under 3 different scenarios: reported actual commuting times (ACT), ideal commuting times (ICT), and maximum willingness to commute (MCT). In addition, binary logistic regression models, estimated using generalized linear modeling (GLM), are performed to assess the impact of these temporal preferences on the likelihood of being satisfied with commuting. As expected, ideal and maximum commuting preferences strongly impact the volume and spatial distribution of the measured accessibility to jobs. In the selected case studies, estimated ICT-based job accessibility significantly decreases total measured accessibility (60 to 100 percent), with those living in the lowest accessibility zones impacted most. Furthermore, although specific results varied between regions, the overall findings show an association between ACT and satisfaction. Likewise, commuting mode is found to be a strong predictor of travel satisfaction. Those actively traveling in all three metropolitan regions tend to be more satisfied with their commutes. Potential job accessibility is found to be only weakly associated with travel satisfaction.
\end{abstract}

Keywords: São Paulo, London, Randstad, commuting satisfaction, accessibility, decay functions

\section{Article history:}

Received: July 8, 2020

Received in revised form:

February 1, 2021

Accepted: May 5, 2021

Available online: September 9, 2021

\footnotetext{
Copyright 2021 John P. Pritchard, Karst Geurs, Diego B. Tomasiello, Anne Dorothee Slovic, Adelaide Nardocci, Prashant Kumar, Mariana Giannotti \& Alex Hagen-Zanker http://dx.doi.org/10.5198/jtlu.2021.1835

ISSN: 1938-7849 | Licensed under the Creative Commons Attribution - Noncommercial License 4.0
}

The Journal of Transport and Land Use is the official journal of the World Society for Transport and Land Use (WSTLUR) and is published and sponsored by the University of Minnesota Center for Transportation Studies. 


\section{Introduction}

In the past decade, the quality and quantity of accessibility research has rapidly increased. This is partly due to the growing abundance of spatial and transport data that has enabled the measurement of temporally disaggregated accessibility indicators. Chief among these emerging data sources is the growth of general transit feed specification (GTFS) data for more accurate public transport (PT) travel times (for a review, refer to Stępniak, Pritchard, Geurs, \& Goliszek, 2019), and congestion data for more accurate car travel times (e.g., Moya-Gómez \& García-Palomares, 2017). In parallel, many studies have examined the relationships between commuting preferences, satisfaction with travel, and well-being (for an overview, refer to Mokhtarian, 2019; Chatterjee et al., 2020). However, there have been few attempts to link both research fields despite improved accessibility and improvements in travel satisfaction often being important goals for transport operators and policy makers. The work presented here aims to bridge these two fields in order to provide additional insight into the subject at hand. This is achieved following a two-pronged approach. First, the impact of preference-based travel times on the value of measured potential job accessibility is explored. Then, the impact of job accessibility on commuting satisfaction is analyzed, controlling for commuting preferences and other factors.

A key addition to the accessibility literature is that, relying on a unique data-set, zonal potential accessibility is calculated under three different scenarios. Different decay functions are estimated for: (1) current actual commuting times (ACT), (2) ideal commuting times (ICT), and (3) maximum willingness to commute times (MCT). Recently, Chaloux et al. (2019) also recognized this gap in the literature, and attempted to introduce satisfaction in accessibility measures. However, the methodology and analysis presented here differs to that of Chaloux et al. (2019). There, accessibility was estimated considering only the travel times of those who reported being satisfied with their commute. Here, participants were directly asked what their ideal commuting times would be as well as their maximum potential thresholds. This information is then used to generate three distinct scenarios. Furthermore, despite the body of literature on commuting satisfaction, the impact of potential job accessibility on commuting satisfaction has not been studied before. We hypothesize that a high level of job accessibility (by a specific mode) can positively affect commuter satisfaction levels. This relates to the link between potential accessibility and option values, as argued by van Wee and Geurs (2016). The option values concept indicates that people in some cases value not just the actual use they make of the transport system, but also the availability of options to travel or carry out activities.

By linking accessibility to employment, commuting desires, and commuting satisfaction this work engages with an underlying assumption central to much of the accessibility literature: the general (implicit or explicit) understanding that more accessibility is valuable and desirable. However, the value of marginal increases in accessibility is not well understood. With the increase of case-specific studies that measure geographic and modal accessibility differences, the question of how to understand and value accessibility is beginning to attract more attention. It is hoped that further insights into this relationship can be provided by simultaneously exploring zonal accessibility levels and the satisfaction of commuters in three different contexts: the Greater London Area (GLA), the Randstad region of the Netherlands (NLR), and the municipality of São Paulo (MSP).

The rest of this article is structured as follows. A brief overview of the literature is provided next. This is followed by the description of the data and methods, with a particular focus on the accessibility and statistical analyses. The general model specification for the estimated binary logistic models for commuting satisfaction is also presented. This is followed by the results for all three case study regions (i.e., GLA, NLR, and MSP). First, reported commuting preferences (Section 4.1) and their impacts on estimated potential accessibility (Section 4.2). Then, the associations between commuting satisfaction and commuting preferences (Section 4.3). Lastly, the discussion and conclusions are presented. 


\section{$2 \quad$ Literature review}

Within the travel behavior field, it is well established that travel times generally impact travel satisfaction. However, there is growing evidence that commuting and subjective well-being should be studied separately from general travel and well-being since they are likely to interact in distinct ways (Chatterjee et al., 2020). More specifically, it has been found that longer commutes tend to result in lower satisfaction in a variety of cultural contexts (e.g., Lancée, Veenhoven, \& Burger, 2017; Zhu \& Fan, 2018). Furthermore, long travel times have been found to negatively impact mood (Morris \& Guerra, 2015).

Despite this general perceived disutility of travel, it has also been long understood that travel has some innate positive utility (e.g., Choo, Collantes, \& Mokhtarian, 2005; Jain \& Lyons, 2008). In fact, most individuals are not interested in minimizing their travel time entirely (i.e., to zero), even while commuting (Redmond \& Mokhtarian, 2001). Furthermore, a range of factors including individual affinities, attitudes and preferences, as well as the transport mode have been shown to mitigate and impact the negative relationship between trip duration and satisfaction (St-Louis et al., 2014). Modal choice is particularly relevant on this front (Chatterjee et al., 2020). Active modes are generally more positively related to travel satisfaction while PT tends to be negatively related. For example, in the Netherlands (where one of the case studies is located), it has been found that individuals are often happy to commute longer if they are either walking or cycling (Lancée et al., 2017). The impact of PT modes on satisfaction is less straightforward. While typically there is lower satisfaction for PT users, train commuters have been found to be significantly more satisfied than car drivers, bus users, and metro users (e.g., St-Louis et al., 2014). On the other hand, long-duration bus commuting has been found to be deleterious for mood (Morris \& Guerra, 2015). Having said this, it has been argued that the modal impact may be overstated. For example, De Vos (2019) argues that the level of satisfaction associated with specific modes is more related to whether the preferred mode is used, than to the characteristics of the modes themselves. Unsurprisingly, liking one's commute mode has been found to be associated with higher commuting satisfaction (Handy \& Thigpen, 2019).

In terms of travel times, travel duration's impact on commuting satisfaction is often mitigated by a number of factors. Among these, the impact of self-selection and choices is particularly relevant. For instance, Morris and Zhou (2018) could not find an association between longer commutes and life satisfaction. The associations that they found for the longer commutes allude to why this may be the case. They found that longer commuting patterns are associated with higher wages, suburban living, higher home ownership rates, and marital status. All of these may be positively associated with subjective wellbeing and satisfaction with life. These findings highlight that the context of the longer commute matters: the land use patterns, demographic patterns of suburbanization (i.e., urban vs. suburban or peripheral poverty), as well as the level of choice in these commutes. For example, in the Netherlands, longer commutes are associated with higher income and higher educated individuals (e.g., van Ham, 2002). In Belgium, De Vos and Witlox (2016) report that travel-liking individuals tend to live in areas that lend themselves to longer commutes, while travel-adverse residents choose more accessible locations.

The interest in accessibility, commonly understood as the ease of reaching opportunities, continues to grow amongst researchers and policymakers. Within the field of location-based accessibility (cf., Geurs \& van Wee, 2004), also referred to as primal accessibility (cf., Cui \& Levinson, 2019), many measures have been developed. Here, we rely on the potential accessibility measure, introduced by Hansen (1959), which weighs the available opportunities (e.g., jobs) using a trip decay function based on travel time or cost. The decay function weighs the accessible opportunities relying on the estimated likelihood that a trip of said length would be made. This function is usually estimated using trip diary data, and is often incorrectly interpreted or assumed to represent commuting preferences. However, these trip lengths, and the frequency of trips of certain lengths are unlikely to be primarily the result of prefer- 
ence. These lengths are a function of the land use distribution, and transport opportunities available. For a large segment of the population the available alternatives can be accurately described as a restricted choice set. Morris, Dumble, and Wigan (1979) already noted that a major disadvantage of using measures of actual travel behavior to evaluate the transport/land use system is the difficulty to disentangle the influence of choices and constraints. This is readily apparent when comparing the accessibility provided by different transport modes. The travel time decay of PT trips is often less steep than for car trips (or other privately owned vehicles), and individuals with a preference or affinity for PT are more likely to tolerate longer waiting times (Shaw, Malokin, Mokhtarian, \& Circella, 2019). However it would be asinine to assume that this is more likely to be the result of individual preferences for longer trips, and not the result of the level of service provided by these systems. For this reason, it has been previously argued that for cross modal comparisons, the same decay function should be used when comparing the car and PT (e.g., Geurs \& Ritsema van Eck, 2001; Pritchard, Tomasiello, Giannotti, \& Geurs, 2019b).

\section{Data and methods}

\subsection{Survey description}

The data used in this analysis was collected between June 2017 and June 2018 in the MSP, the GLA, and the NLR (which includes Rotterdam, Utrecht, The Hague and Amsterdam).

The survey explored residents' perceptions of their built environment and the associated exposure to air pollution in order to examine the relationship between job accessibility, air pollution exposure and social justice. This was done by collecting information related to their choices, or lack thereof, in selecting their residential and/or work locations. It was composed of three main sections: Commuting and Employment, Housing, and Pollution and Health. The latter addressed perceptions of air pollution, followed by sections on the respondents' current employment and housing reality as well as their decision-making process for selecting their home and employment locations. General socio-demographic information of the samples was also collected. The guiding principle during the design of the survey was to collect a unique data-set that successfully bridged the gap between the existing secondary (land use and transport) and experimental data (pollution measurements) in order to enhance and complement the analysis. The analysis presented here relies on the commuting and employment section of the survey.

In terms of commuting, respondents in the GLA, NLR and MSP reported their commuting satisfaction, their commuting duration preferences (ICT and MCT), and their ACT. As will be described in more detail in Sections 3.3 and 3.4, this information is used to estimate potential accessibility models and included as explanatory variables in the generalized linear modeling (GLM) estimations of commuting satisfaction in the three case study regions. Specifically, respondents answered the following questions:

1. ACT: Roughly how long is your commute from home to work, in minutes, on a typical day?

2. ICT: Ideally, if you could choose, how long would you like your commute to be? (in minutes)

3. MCT: How long do you think you would be willing to commute? (in minutes)

Given the nature of the analysis, list-wise deletion was applied when working with the survey data. Respondents that did not report their commuting preferences were not included in the statistical analysis. In practice this meant that the unemployed sample was completely excluded $(n=884)$. Additionally, respondents who reported having a lower commuting willingness than their ideal commute (i.e., $\mathrm{MCT}<\mathrm{ICT}$ ) were also eliminated, as were those reporting a longer ACT than their reported MCT. 
It was assumed that these respondents had responded mistakenly, or misinterpreted the question. Furthermore, for the statistical analysis, individuals who did not report their residential area, or satisfaction were also excluded. The resulting sample size $(\mathrm{n})$ after the deletions was $2644\left(\mathrm{n}_{\mathrm{GLA}}=716, \mathrm{n}_{\mathrm{MSP}}=579\right.$, $\mathrm{n}_{\mathrm{NLR}}=1227$ ).

\subsection{Sampling and case study areas}

For the GLA and the NLR, the areas were stratified based on a two-stage stratification criterion following the general procedure presented in part by Cerin, Leslie, du Toit, Owen, \& Frank (2007). The stratification variables differed from the aforementioned project given the thematic differences. The twostage stratification consisted of ranking all the sub-areas of the GLA and the NLR in terms of income and accessibility. Using these two criteria the areas were grouped into four income strata, each with two substrata in terms of their accessibility levels.

The sampling in the MSP differed from the other case study areas since it involved in-person visits to the surveyed households. Two-stage cluster sampling was performed with geographic (city zone) and socioeconomic stratification of census tracts from the database of the 2010 IBGE Demographic Census. The secondary units were the permanent households in each census tract. The census tracts were selected by systematic sampling proportional to the number of households while households were selected by simple random sampling. The city was divided into five zones and in four socioeconomic groups based on the percentiles values of Municipal Human Development Index (MHDI) by census tracts obtained by Ribeiro et al. (2019): Very Low ( < 10th ), Low 10th - 50th), High (50th - 90th) and Very High (> 90th of the MHDI). The survey was submitted and received approval from the Brazilian Ethical Committee, CAAE 62918316.0.0000.54211.

\subsection{Accessibility analysis}

Zonal potential accessibility to jobs is estimated following the general form proposed by Hansen (1959):

$A_{i}=\sum_{j} o j \cdot f\left(t_{i j}\right)$

Where $A_{i}$ is the potential accessibility by a particular mode x in any location $\mathrm{i} ; o_{j}$ is the number of opportunities (i.e., jobs) in any location $\mathrm{j}$; and $\mathrm{f}\left(\mathrm{t}_{\mathrm{ij}}\right)$ is an impedance function based on travel time by the selected mode $\mathrm{x}$ from location $\mathrm{i}$ to $\mathrm{j}$.

Here, we estimate job accessibility by PT. GTFS is used to estimate travel time matrices for SP and the NLR every 15 minutes during the morning peak (6:00 a.m. to 9:00 a.m.). Travel times are calculated using the Network Analyst extension of ArcGIS and the network database is built using the Add GTFS to a Network Dataset tool. For the GLA, WebCAT Time Mapping (TIM) is used because GTFS was not available. Employment data-sets are taken from NS-SEC 2011 (ONS, 2017) in the GLA, LISA 2014 (Stichting LISA, 2014) in the NLR, and combined data from RAIS 2009 and CNEFE 2010 (García-López \& Moreno-Monroy, 2016) is used in the MSP. For a detailed description of the methodology and data refer to Pritchard et al. (2019a).

The key addition to the accessibility literature is that, due to the use of a unique multi-national survey, zonal potential accessibility is calculated under three different scenarios and in three different contexts using the same survey questions. Different decay functions are estimated for: (1) ACT (2) ICT, and (3) MCT using non-linear regression based on the preferences of the participants of the ASTRID project survey. The functions are selected relying on the Akaike Information Criterion (AIC). 


\subsection{Statistical analysis}

In addition to the geographical impacts in terms of the zonal accessibility, binary logistic regression models, estimated using GLM, are performed in order to explore the relationship between commuting time, commuting preferences, and personal characteristics. The modeling work was performed using the R (version 3.6.1) statistical software (R Core Team, 2020) and the VGAM package (Yee, 2015).

Three models are presented, one for each of the case study areas, in order to understand how these relationships vary between the different contexts. Commuter satisfaction is modeled as a binary variable. The general hypotheses underlying the models are as follows:

Duration is expected to negatively associate with commuting satisfaction: All else equal, as ACT increases, the likelihood of reporting being satisfied with commuting is expected to decrease.

Commuting preferences are expected to mediate this association: Those with higher tolerances, i.e., a stated willingness to commute longer (MCT), are expected to be more likely to be satisfied with their current commute. Additionally, those with longer ICT are also more likely to be more satisfied. This is because they are more likely to have been able to select a combination of residential and employment locations that matches their preferences.

Additionally, the relationship between ACT and ICT is expected to be particularly relevant. Lower dissonance between ACT and ICT has been found to be positively associated with commuting satisfaction due to preferences being met (Humagain \& Singleton, 2020; Ye, De Vos, \& Ma, 2020).

Modal choice is expected to have an impact: In line with the literature (as described in Section 2), active travel is expected to have a strong positive relationship. A positive but less strong impact is expected for individuals that report commuting with several modes, including active and transit, but never commuting by private car.

Higher zonal accessibility is expected to positively impact satisfaction: This is expected to be a complex relationship. Therefore, the level of accessibility is not expected to show a clear positive association to commuting satisfaction. Instead, it is hypothesized that at certain levels, the accessibility is likely to be linked to satisfaction, but not at the highest levels.

Reporting negative consequences will negatively associate with satisfaction: Those reporting negative impacts due to commuting or other transport-related problems are likely to be less satisfied with said commute. Although satisfaction can be influenced by expectations, it is hypothesized that affirming that commuting is negatively impacting other aspects or your life, should result in lower likelihood of still reporting being satisfied.

Higher subjective well-being is likely to positively associate with commuting satisfaction: General satisfaction with life (i.e., subjective well-being) is likely to result in higher satisfaction with commuting, but this is not expected to be particularly strong. The relationship between well-being and travel satisfaction is complex, but it is hypothesized that those who are generally satisfied are more likely to be satisfied with this or any other aspect of their lives.

\subsubsection{Description of included target and explanatory variables}

The target variable is a simple binary variable of commute satisfaction, where 1 is individuals who are satisfied with their commute, and 0 those who are not. This variable was created from a single 5 -point Likert scale question. Respondents who reported being satisfied or very satisfied were assigned as "satisfied." While the possibility of treating the variable as ordinal was explored, the response profiles in the different case study regions necessitated the transformation of the variable. Particularly in the NLR, but also in the GLA, there were very high numbers of individuals reporting being satisfied, and very few being either very dissatisfied or dissatisfied. As a result, even with good model fit indices, the model was 
unlikely to correctly predict the individuals in particularly small groups. (More details and descriptive analysis of these responses can be found in Section 4.3.1.)

Commuting times (ICT, ACT, and MCT) are included in 10-minute intervals, rounded to the nearest tens, in order to more easily interpret the results. That is, an increase of 1 in the model represents a 10-minute increase in commuting time. As can be seen in Table 6 , when compared to the descriptive results shown in Table 1, this leads to slight increases in the means, but not significantly so. Given the benefits for the intelligibility of the results, as well as the fact that we tend to estimate time in intervals (resulting in many numbers never being named as commuting times) it was decided that this was a worthwhile transformation. Additionally, it should be noted that ACT and MCT were highly and significantly correlated (0.78), while the correlation between ACT and ICT was less strong, albeit still significant (0.59).

Additionally, in order to assess the dissonance between ACT and ICT, a binary variable is included that differentiates respondents who are able to achieve their ICT (i.e., ACT $\leq$ ICT).

Modal choice is included as distinct binary variables: always commuting actively (i.e., walking and/ or cycling), always commuting by private car, mixed commuting that never includes the car (i.e., commuting by PT and other alternatives as well), and mixed commuting that may include the car. As highlighted in section 3.4, active commuters are expected to report higher satisfaction with their commutes. As such, it was important to be able to distinguish this group in the sample. Likewise, it was relevant to distinguish those who only commuted by car, since they were expected to perceive travel times differently and have different expectations that would impact their satisfaction. Therefore, those who reported using multiple modes to regularly commute were divided to include a subset that, although not only commuting actively, never used the car.

Zonal accessibility values (see section 4.2.2) are assigned to each of the respondents based on their residential area. Although three accessibility values are estimated for each zone, they are highly correlated amongst each other. Therefore, in order to avoid collinearity issues, only the potential accessibility estimated based on ICT is included. Additionally, an analysis of the distribution of accessibility for the respondents shows a right-skewed distribution with long tails. Given the long tails, the log of the accessibility is tested in the model. This is done in order to decrease the impact of very high accessibility under the assumption that the relationship would not continue to increase as the values continue to grow larger and larger. Coefficients on the natural-log scale are directly interpretable as approximate proportional differences (Gelman \& Hill, 2007).

In terms of transport difficulties, two different binary variables are included. The first is having experienced negative impacts due to commuting duration. In the survey, respondents were asked whether they believed that the amount of time they spent commuting prevented or limited other aspects of their life. We hypothesize that those who report these negative impacts to their lives are less likely to be satisfied with their commute. Additionally, car ownership is also included as a potential transport difficulty. While car ownership can be a choice, it also limits commuting options.

To include a general measure of subjective well-being, the widely validated and often used Satisfaction with Life Scale (SWLS) developed by Diener (1985) is used. The scores range from 5-35, with an average score of 20-24 corresponding to average life satisfaction in developed countries. That is, they are generally satisfied but would like some improvement at least in some areas (Diener, 2006). The results can be used as either a continuous scale or as an ordinal scale, with particular ranges corresponding to states of satisfaction. The ordinal scale is used in the models.

Finally, several personal characteristics are tested in the model. Age is modeled as a continuous variable, and both the age and the squared age are tested. By including both it is then possible to model a nonlinear relation of age, e.g., if there is positive effect of age and a negative effect of age squared then this could be interpreted as a lessening of the effect as age increases. On the other hand, a positive effect 
in both would indicate the effect grows stronger with age. Gender is included as a binary variable, with women coded as 1 and men as 0 . Educational attainment is also tested as a binary variable, to identify respondents with more than a high-school education.

\section{$4 \quad$ Results}

\subsection{Reported commuting preferences: ACT, ICT, and MCT}

The descriptive results of the commuting duration preferences (ACT, ICT, and MCT) in each of the case study regions can be found in Table 1 . The NLR reported the lowest average ACT ( $\approx 24 \mathrm{~min}$.), as well as the lowest ICT $(\approx 17 \mathrm{~min}$.) and MCT $(\approx 42 \mathrm{~min}$.). The GLA and MSP reported similar ideal commutes $(\approx 20 \mathrm{~min}$.). However, despite the respondents in the GLA reporting slightly longer average current commutes ( $\approx 34$ and $32 \mathrm{~min}$., respectively), the Brazilians reported a higher maximum willingness to commute( $\approx 58 \mathrm{~min}$.), than their counterparts in England $(\approx 51 \mathrm{~min}$.). The London results are comparable to the National Travel Survey data for England, which indicates that the average one-way commute duration is $31 \mathrm{~min}$ (DfT, 2018a) with 14\% of commuters reporting commutes longer than an hour (DfT, 2018b).

Table 1. Actual, ideal, and maximum commuting times (in minutes)

\begin{tabular}{llccr}
\hline & Type & Mean & Median & Stdev \\
\hline \multirow{2}{*}{ GLA } & Actual Commute Time (ACT) & $34.3 \mathrm{~min}$ & $30 \mathrm{~min}$ & $23.7 \mathrm{~min}$ \\
& Ideal Commute Time (ICT) & $19.9 \mathrm{~min}$ & $19 \mathrm{~min}$ & $14.1 \mathrm{~min}$ \\
& Max. Willingness to Commute Time (MCT) & $51.1 \mathrm{~min}$ & $50 \mathrm{~min}$ & $27.9 \mathrm{~min}$ \\
\hline \multirow{2}{*}{ MSP } & Actual Commute Time (ACT) & $32.3 \mathrm{~min}$ & $20 \mathrm{~min}$ & $33.6 \mathrm{~min}$ \\
& Ideal Commute Time (ICT) & $20.4 \mathrm{~min}$ & $15 \mathrm{~min}$ & $16.9 \mathrm{~min}$ \\
& Max. Willingness to Commute Time (MCT) & $57.5 \mathrm{~min}$ & $60 \mathrm{~min}$ & $38.4 \mathrm{~min}$ \\
\hline \multirow{2}{*}{ NLR } & Actual Commute Time (ACT) & $23.7 \mathrm{~min}$ & $20 \mathrm{~min}$ & $16.2 \mathrm{~min}$ \\
& Ideal Commute Time (ICT) & $16.6 \mathrm{~min}$ & $15 \mathrm{~min}$ & $10.0 \mathrm{~min}$ \\
& Max. Willingness to Commute Time (MCT) & $41.5 \mathrm{~min}$ & $40 \mathrm{~min}$ & $21.2 \mathrm{~min}$ \\
\hline \multirow{2}{*}{ Total } & Actual Commute Time (ACT) & $28.7 \mathrm{~min}$ & $25 \mathrm{~min}$ & $24.0 \mathrm{~min}$ \\
& Ideal Commute Time (ICT) & $18.4 \mathrm{~min}$ & $15 \mathrm{~min}$ & $13.2 \mathrm{~min}$ \\
& Max. Willingness to Commute Time (MCT) & $48.0 \mathrm{~min}$ & $45 \mathrm{~min}$ & $28.8 \mathrm{~min}$ \\
\hline
\end{tabular}

On average, respondents reported current unidirectional times of approximately 29 minutes, but a desire that was approximately 10 minutes shorter. They reported a maximum average tolerance of almost 50 minutes $(\approx 48 \mathrm{~min}$.). Very few respondents reported an ICT of more than 30 minutes, with most reporting an ICT between 10 and 20 minutes. In terms of MCT, respondents seemed to use rougher estimates, with most responding with $30,40,45$, or 60 minutes.

Furthermore, as is visible in Figure 1 and Figure 2 there is a general positive relationship between both the ICT and MCT, and the current commuting patterns, i.e., as ACT increases so does the MCT and the ICT. This points to individuals potentially anchoring their desires. Exploring the desired ideal commuting in more detail (see Table 2), it becomes evident that most respondents do not currently achieve their ICT. The percentage of the sample that reported a current ACT that was lower than their ICT ranged between $5.7 \%$ in the GLA and $18.7 \%$, in the MSP. This is in line with the findings of Ye et al. (2020) in China, who reported $17.1 \%$. The majority of the sample in each of the cases reported 
current commuting times higher than their ideal, but it was in the GLA where this was most marked with $\approx 70 \%$ of the sample reporting commuting times higher than their ideal.
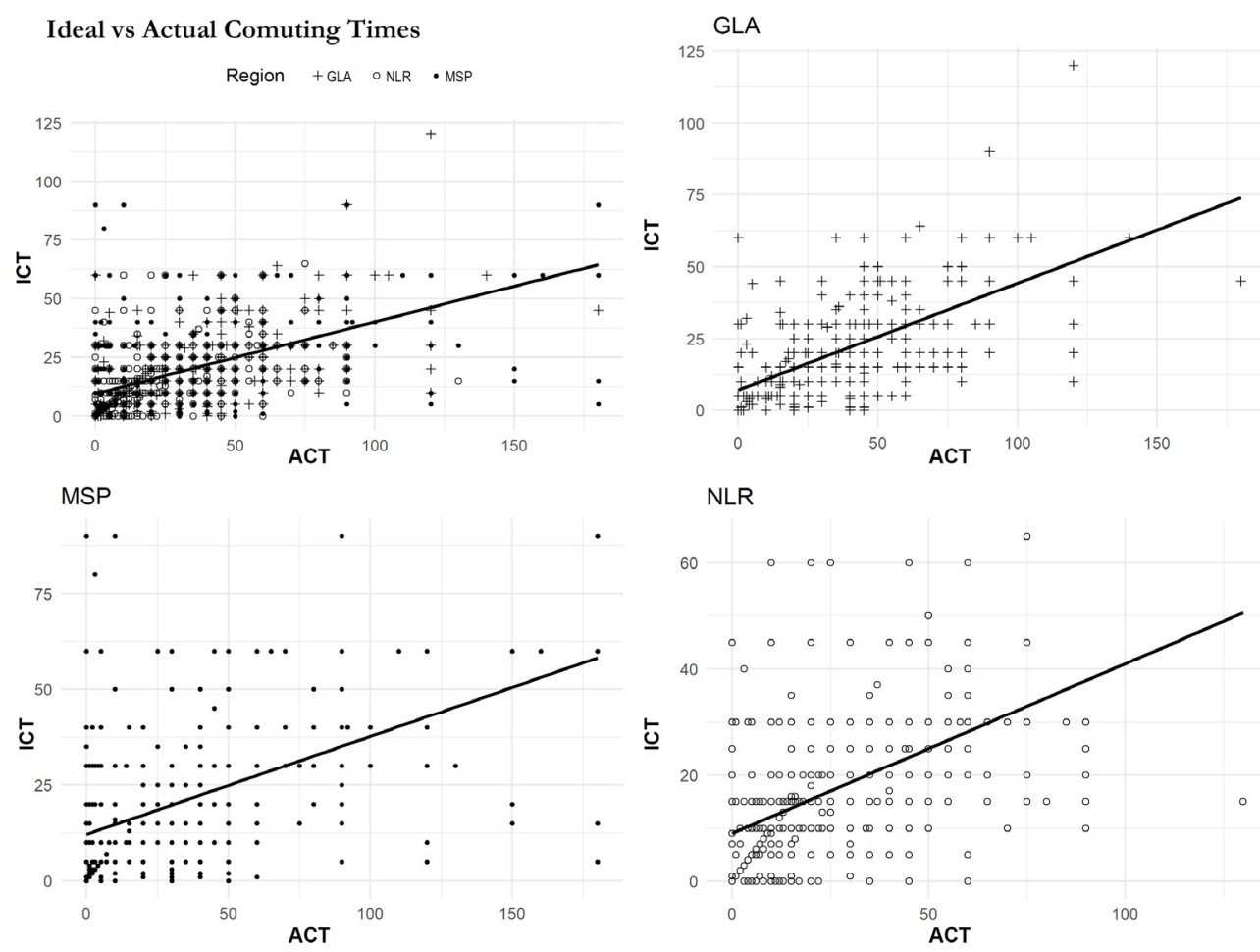

Figure 1. Scatter plot of desired ideal vs. current commuting
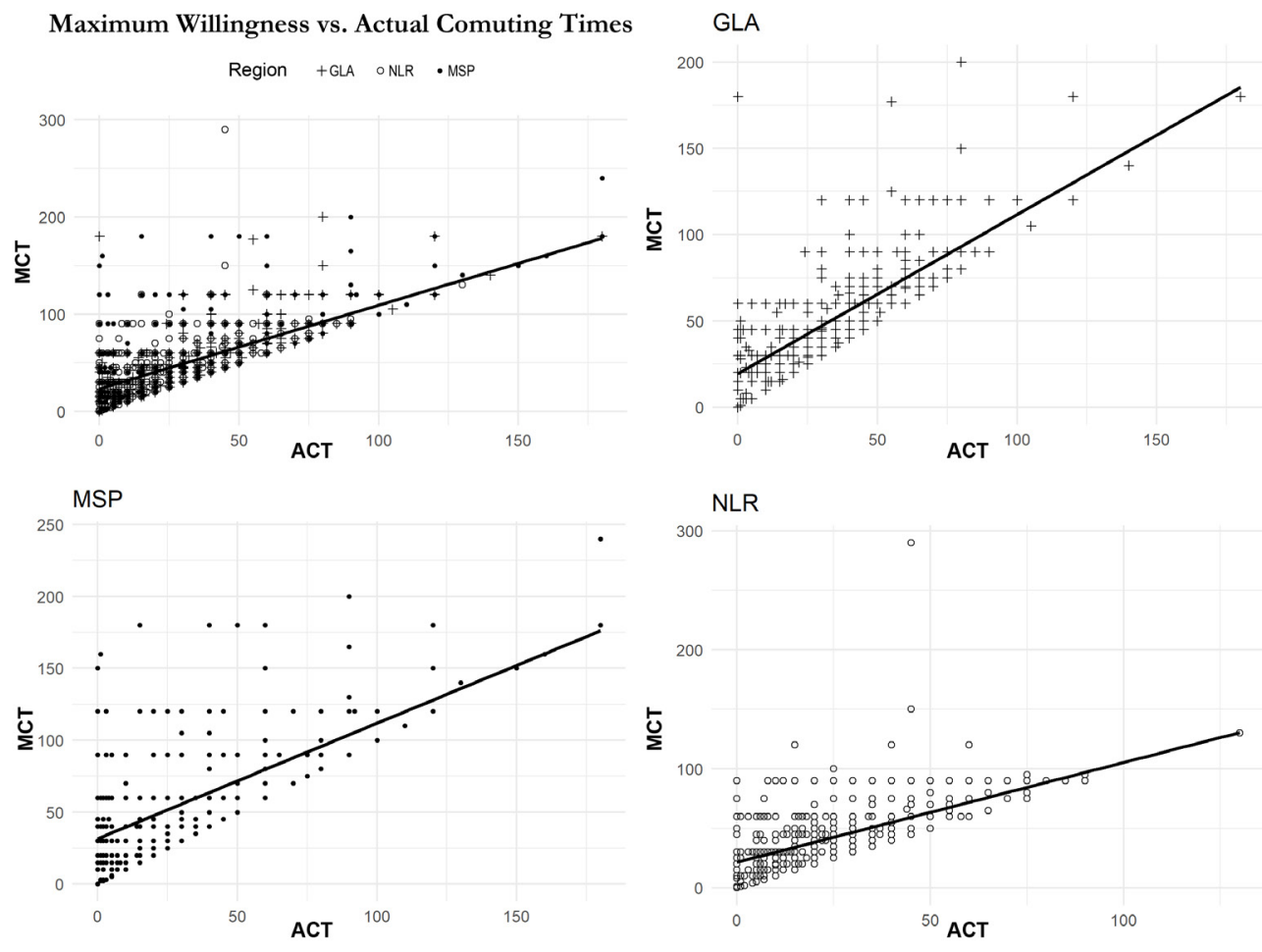

Figure 2. Scatter plot of willingness vs. current commuting 
Table 2. Difference between actual and ideal commutes by mode (ACT vs. ICT)

\begin{tabular}{llrrrrr}
\hline & & Always Car & Never Car & Always Active & Other & Total \\
\hline \multirow{2}{*}{ ACT $<$ ICT } & GLA & $4(9.5 \%)$ & $12(28.7 \%)$ & $4(9.5 \%)$ & $22(52.4 \%)$ & $\mathbf{5 . 7 \%}$ \\
& MSP & $8(6.7 \%)$ & $12(10.1 \%)$ & $53(44.6 \%)$ & $46(38.6 \%)$ & $\mathbf{1 8 . 7 \%}$ \\
& NLR & $40(25.7 \%)$ & $20(12.8 \%)$ & $48(30.8 \%)$ & $48(30.8 \%)$ & $\mathbf{1 2 . 1 \%}$ \\
\hline \multirow{2}{*}{ ACT = ICT } & GLA & $26(14.4 \%)$ & $42(23.3 \%)$ & $24(12.3 \%)$ & $88(48.9 \%)$ & $\mathbf{2 4 . 4 \%}$ \\
& MSP & $49(26.4 \%)$ & $43(23.1 \%)$ & $75(40.3 \%)$ & $19(8.9 \%)$ & $\mathbf{2 9 . 3 \%}$ \\
& NLR & $172(37.3 \%)$ & $24(5.2 \%)$ & $138(29.9 \%)$ & $127(27.6 \%)$ & $\mathbf{3 5 . 7} \%$ \\
\hline \multirow{2}{*}{ ACT $>$ ICT } & GLA & $105(20.4 \%)$ & $256(49.6 \%)$ & $31(6.0 \%)$ & $124(24.0 \%)$ & $\mathbf{6 9 . 9} \%$ \\
& MSP & $80(24.2 \%)$ & $187(56.7 \%)$ & $29(8.8 \%)$ & $34(10.3 \%)$ & $\mathbf{5 2 . 0} \%$ \\
& NLR & $340(50.5 \%)$ & $105(15.6 \%)$ & $95(14.1 \%)$ & $134(19.9 \%)$ & $\mathbf{5 2 . 2} \%$ \\
\hline Total & & $\mathbf{8 2 4}(30.9 \%)$ & $\mathbf{7 0 1}(26.3 \%)$ & $\mathbf{4 9 7}(18.7 \%)$ & $\mathbf{6 4 2}(24.1 \%)$ & $\mathbf{n = 2 , 6 6 4}$ \\
\hline
\end{tabular}

Considering modal choice, in the NLR and the MSP, the largest segments of the population reporting a desire for longer commuting (i.e., ICT > ACT), were those who always commute actively $(30.8 \%$ and $44.6 \%$ ). The smallest segment was made up of those reporting to always commute by car (or other private mode), with the NLR and GLA reporting less than $10 \%$ and the MSP $\approx 26 \%$. This is interesting for two different reasons; first, despite the car providing higher accessibility to jobs in all three cities (e.g., Pritchard, Tomasiello, Giannotti, \& Geurs, 2019a), and the car providing greater flexibility in terms of departure times we see that most car commuters would still like to have shorter commutes. Secondly, the higher satisfaction rates of active commuters is in line with previous findings; active commuters are often happy to commute longer if they are either walking or cycling (e.g., Lancée et al., 2017).

\subsection{ACT, ICT, and MCT-based potential accessibility}

\subsubsection{Travel decay functions based on commuting preferences}

Travel decay functions were estimated relying on the ACT, ICT, and MCT. The results of the decay estimations (measured in travel time) for each of the case study areas can be found in Table 3 and the estimated curves in Figure 3.

Table 3. Estimated decay functions: ACT, ICT, and MCT

\begin{tabular}{|c|c|c|c|c|c|}
\hline & & GLA & MSP & & NLR \\
\hline ICT & $\begin{array}{l}\text { Log-Logistic } \\
\alpha=-8.669\end{array}$ & $\beta=3.198$ & $\begin{array}{l}\text { Negative Exponential } \\
\alpha=-0.060\end{array}$ & $\begin{array}{l}\text { Log-Logistic } \\
\alpha=-6.719\end{array}$ & $\beta=2.692$ \\
\hline ACT & $\begin{array}{l}\text { Log-Logistic } \\
\alpha=-7.420\end{array}$ & $\beta=2.259$ & $\begin{array}{l}\text { Negative Exponential } \\
\alpha=-0.034\end{array}$ & $\begin{array}{l}\text { Log-Logistic } \\
\alpha=-6.445\end{array}$ & $\beta=2.242$ \\
\hline MCT & $\begin{array}{l}\text { Log-Logistic } \\
\alpha=-11.648\end{array}$ & $\beta=3.148$ & $\begin{array}{l}\text { Log-Logistic } \\
\alpha=-9.032 \quad \beta=2.460\end{array}$ & $\begin{array}{l}\text { Log-Logistic } \\
\alpha=-10.947\end{array}$ & $\beta=3.176$ \\
\hline
\end{tabular}


GLA

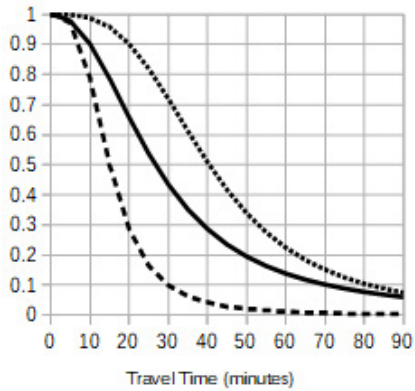

MSP

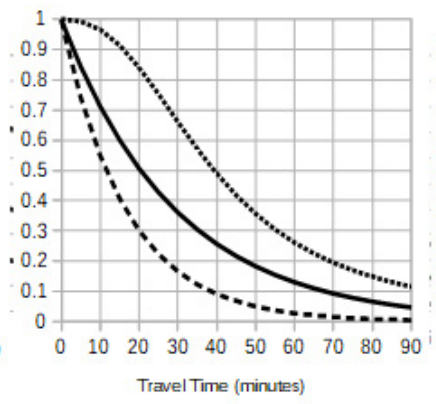

NLR

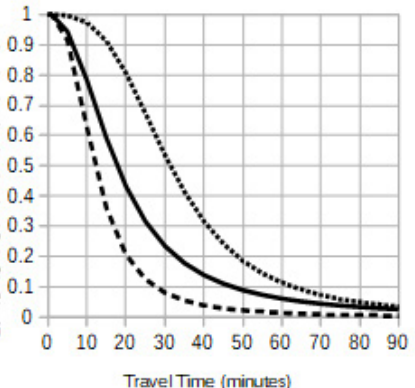

MCT

Figure 3. Estimated variable decay functions in the GLA, MSP, and NLR

The estimated decay function for the current commuting (estimated using ACT) varies from the estimation reported in other studies relying on large mobility travel surveys for the same areas (e.g., Pritchard et al., 2019a). This is to be expected, considering the differences in size of the sample and the fact that they were collected in different years. However, the best fitting model is the same for each of the case studies, albeit with differing values, i.e., the decay follows a similar pattern, but the degree at which it decays varies. Given the focus of the analysis being presented (comparing against the reported commuting preferences), all results and subsequent references to the estimation of the decay of current commuting, will rely on the estimations found in Table 3. It is also interesting to note, that in the case of the MSP, the MCT-based decay function, follows a similar pattern (log-logistic) to the other two case studies, despite showing a negative exponential fit for the current ACT and the ICT.

\subsubsection{Impacts of zonal accessibility measurement}

These distinct decay functions result in vastly different accessibility profiles for each of the three scenarios. The total differences in accessibility are shown in Figure 4, and the relative changes in Figure 5. As expected, the estimated ICT-based accessibility is significantly lower than the accessibility based on the ACT, and the MCT-based accessibility is higher than the other scenarios.

When considering the ICT, on average, there was a zonal accessibility reduction of $85 \%, 73 \%$, and $71 \%$, respectively, in the GLA, MSP, and NLR. The centers of the cities are still found to have the highest accessibility to jobs, but under the ideal scenario the estimated values in these areas are comparable to middling accessibility levels under the current ACT scenario in all three case areas.

As is evident from the descriptive statistics found in Table 4, the range of the zonal impact is larger when considering MCT. In the MSP, despite respondents already having longer commutes, their willingness to commute further was such that the associated average zonal increase in accessibility was above $100 \%$. As evidenced by Figure 5, this was due to the increases in the areas outside the CBD (and the metro coverage). In the GLA, the opposite phenomenon is observed. There is a larger percentage decrease when relying on ICT for the accessibility estimation than the equivalent percentage increase when using the reported MCT. Finally, in the NLR, where respondents were closer to their desired commuting time, we can see that the impact of using ICT to measure accessibility is much lower than in the GLA and the MSP. 
Potential Accessibility by Public Transport with Variable Travel Time Decays
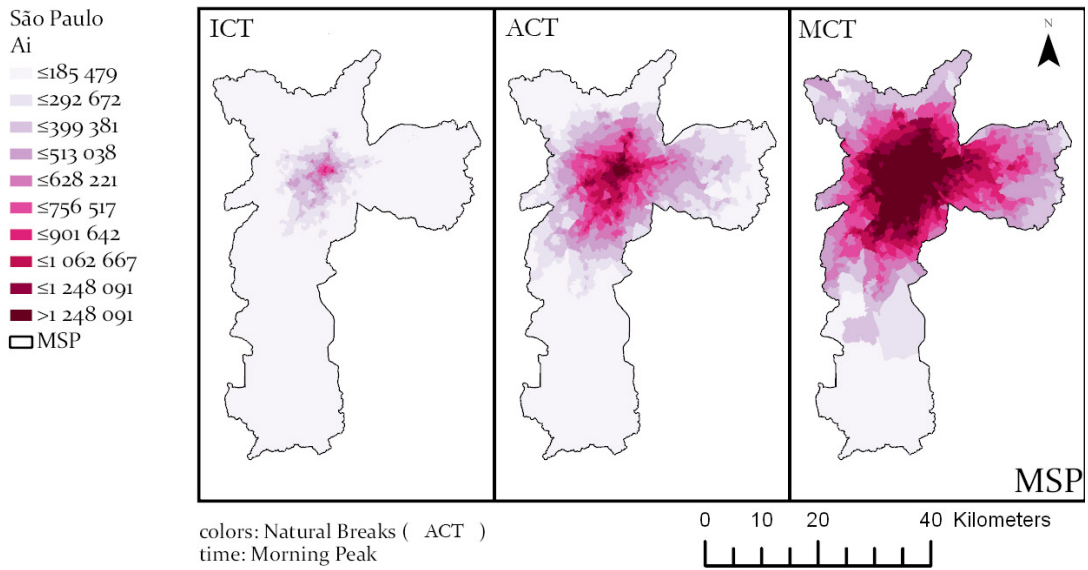

London
$\begin{aligned} \mathrm{Ai} \\ \quad \leq 417986 \\ \leq 524411 \\ \leq 634590 \\ =\leq 755584 \\ =\leq 888141 \\ =1032303 \\ \square \leq 1197622 \\ \square \leq 1399579 \\ \square \leq 1617330 \\ \square>1617330\end{aligned}$

$\square$ GLA

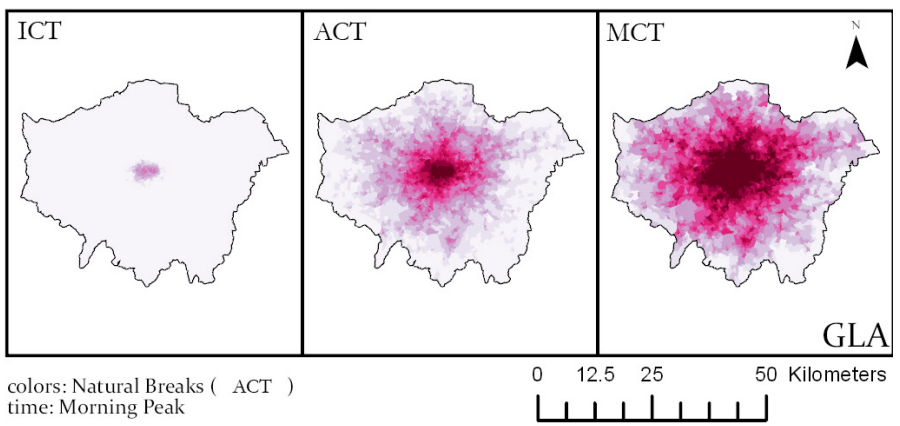

Randstad

$\mathrm{Ai}$

$\leq 15904$

$\leq 32274$

$\leq 49692$

$\square \leq 69249$

$\leq 91806$

$\leq 116404$

$\leq 144363$

- $\leq 183767$

ש $\leq 238200$

- $>238200$

$\square N L R$

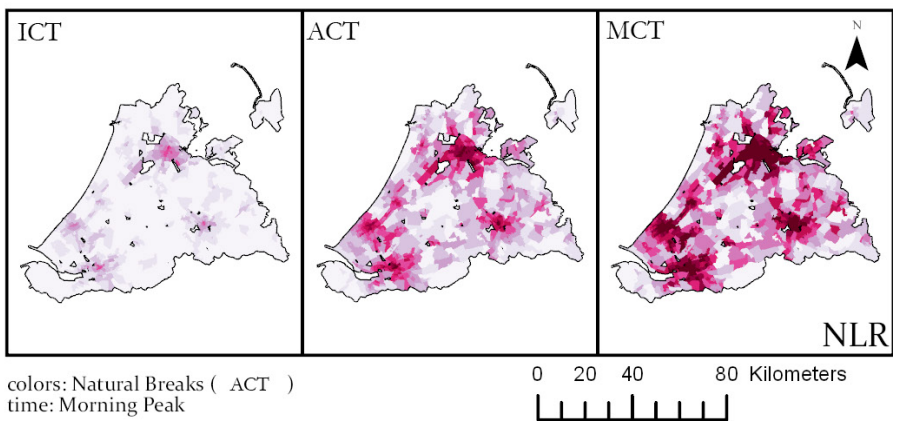

Figure 4. Geographical impacts of variable travel decay functions on accessibility measurements in the GLA, MSP, and NLR 
Absolute Percentage Change in Potential Accessibility with Variable Travel Time Decays
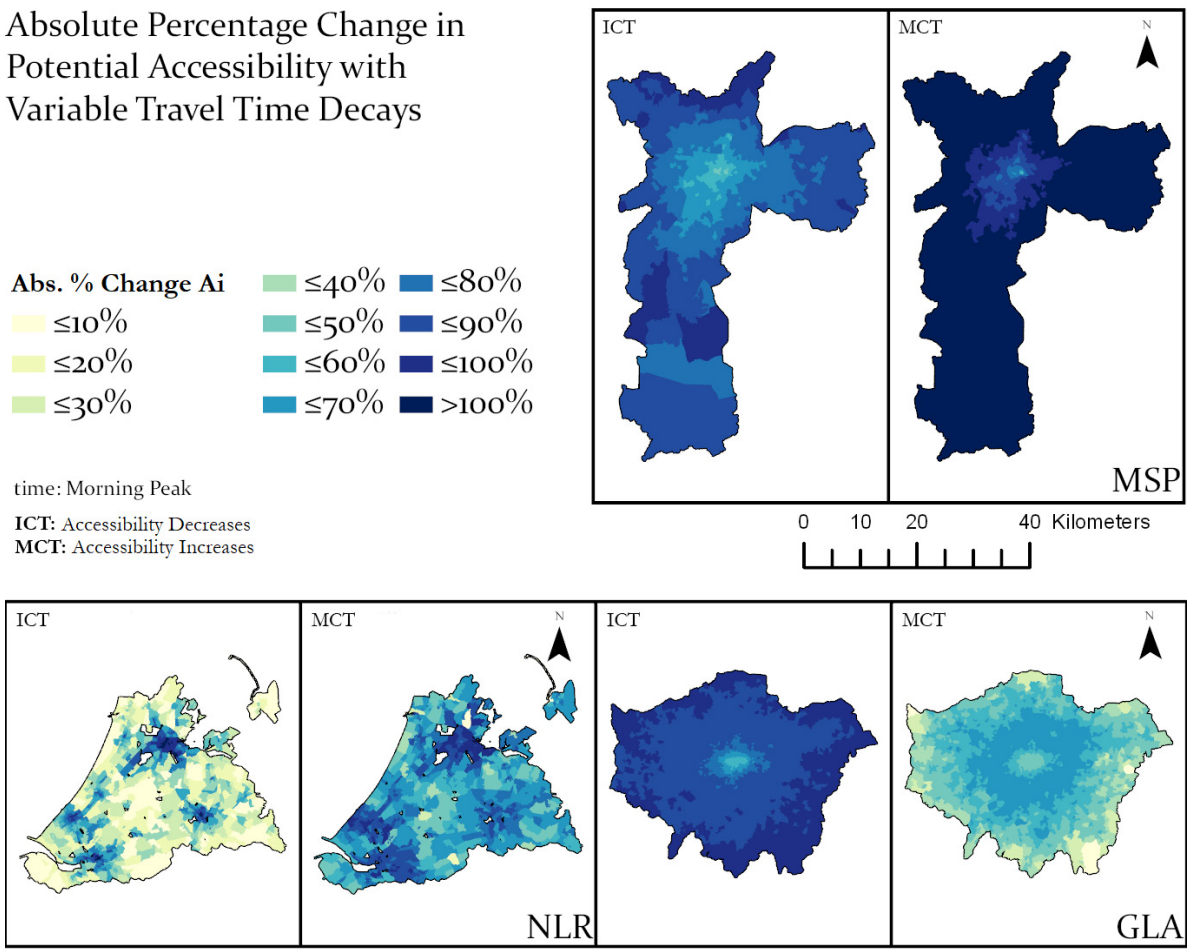

Figure 5. Percentage change in accessibility with variable decay functions in the GLA, MSP, and NLR

Table 4. Descriptive statistics of accessibility results

\begin{tabular}{llrrrrr}
\hline & & Mean & Median & Min & Max & Stdev \\
\hline ICT-based & GLA & 147,867 & 86,170 & 4,877 & 833,223 & 162,249 \\
& MSP & 185,659 & 142,679 & 160 & 856,921 & 161,185 \\
& NLR & 24,222 & 18,317 & 108 & 139,857 & 21,014 \\
\hline \multirow{2}{*}{ ACT-based } & GLA & 781,689 & 684,768 & 121,179 & $1,857,820$ & 365,576 \\
& MSP & 581,220 & 553,023 & 4,962 & $1,552,535$ & 326,382 \\
& NLR & 81,935 & 70,733 & 187 & 331,018 & 60,023 \\
\hline \multirow{2}{*}{ MCT-based } & GLA & $1,231,619$ & $1,112,586$ & 113,142 & $2,664,795$ & 569,624 \\
& MSP & $1,156,596$ & $1,120,045$ & 73,987 & $2,609,393$ & 326,382 \\
& NLR & 149,231 & 125,332 & 233 & 601,484 & 114,510 \\
\hline
\end{tabular}


As shown in Figure 6 and Table 4, the total range of accessibility values experienced by the NLR sample is much more limited than in the MSP and GLA. Additionally, the relationship between the accessibility results based on ACT and those based on MCT tend to follow a generally linear pattern in all three cases. However, for those experiencing the highest levels of accessibility, there is a slight tapering off in terms of the potential gains. This is particularly evident in the GLA. In terms of the ICT-based accessibility, the opposite pattern is found. Although there are significant decreases in total measured accessibility, it is those living in the highest accessibility zones who are impacted the least, reinforcing the general spatial pattern found in Figure 4.
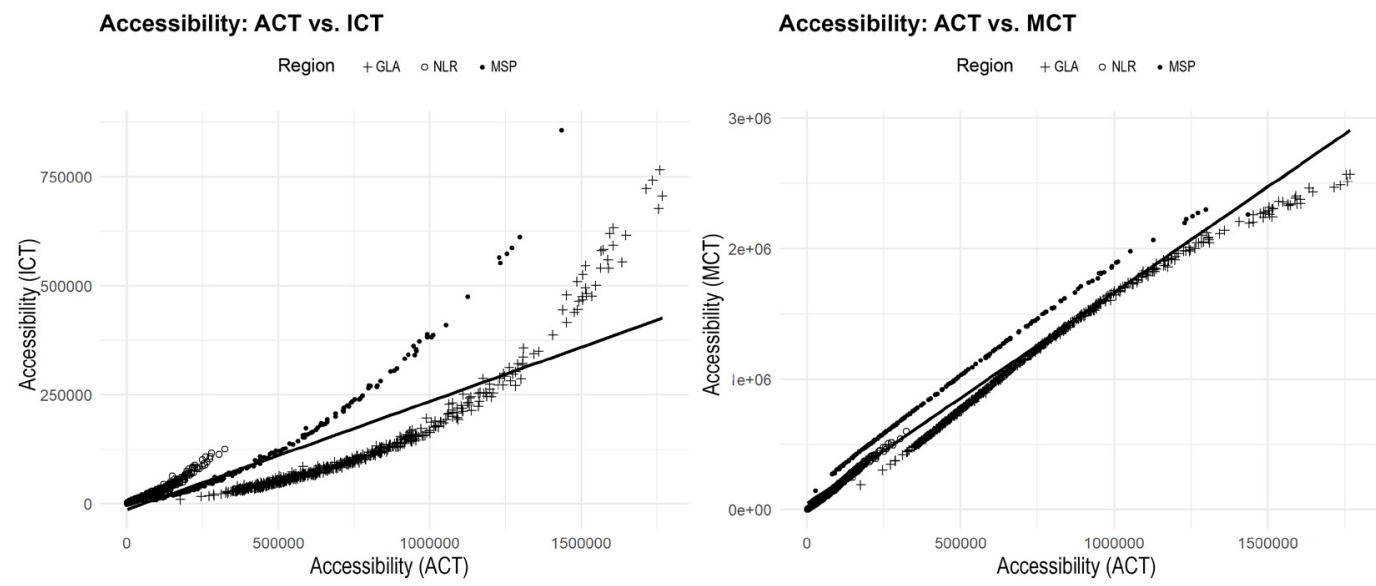

Figure 6. Accessibility impacts of commuting desires in the GLA, MSP, and NLR

Taken together, these findings show that currently, if individual commuting desires are considered, very few areas of the case study regions actually provide their residents with high potential accessibility to jobs. This is relevant because it calls into question how accessibility goals should be set within policy making and how policy results should be analyzed.

\subsection{Commuting satisfaction}

\subsubsection{Impacts of zonal accessibility measurement}

As highlighted in Table 5, the level of reported satisfaction with commuting was particularly high in the NLR, where $82 \%$ reported being at least satisfied, and $87 \%$ of those reporting that they were very satisfied with their commute. In the GLA, 71\% reported being satisfied, with $62 \%$ of those in turn reporting being very satisfied. On the other hand, in the MSP, less than half of the respondents (40\%) reported being satisfied with their commutes, with $52 \%$ of those reporting to be very satisfied. 
Table 5. Satisfaction with commuting: GLA, MSP, and NLR

\begin{tabular}{llrrr}
\hline & Likert Scale & GLA & MSP & NLR \\
\hline Not Satisfied & 1 & $13(2 \%)$ & $41(6 \%)$ & $10(1 \%)$ \\
& 2 & $61(8 \%)$ & $47(7 \%)$ & $65(5 \%)$ \\
& 3 & $118(16 \%)$ & $245(39 \%)$ & $119(9 \%)$ \\
$\mathbf{n}_{\text {not satisfied }}$ & & $\mathbf{1 9 2 ( 2 6 \% )}$ & $\mathbf{3 3 3 ( 5 2 \% )}$ & $\mathbf{1 9 4}(\mathbf{1 5 \% )}$ \\
\hline Satisfied & 4 & $199(27 \%)$ & $121(19 \%)$ & $141(11 \%)$ \\
& 5 & $326(44 \%)$ & $130(20 \%)$ & $924(72 \%)$ \\
$\mathbf{n}_{\text {not satisfied }}$ & & $\mathbf{5 2 5}(\mathbf{7 1 \% )}$ & $\mathbf{2 5 1 ( 4 0 \% )}$ & $\mathbf{1 0 6 5 ( 8 2 \% )}$ \\
\hline Missing & $\mathrm{n} / \mathrm{a}$ & $21(3 \%)$ & $51(8 \%)$ & $32(2 \%)$ \\
Total (n) & & $\mathbf{7 3 8}$ & $\mathbf{6 3 5}$ & $\mathbf{1 2 9 1}$ \\
\hline
\end{tabular}

Further exploring the modal choice, it is found that in the NLR $43 \%$ of the selected sample always commutes by car, while these numbers are only 19\% in the GLA and 23\% in the MSP. In terms of always commuting actively (either on foot or cycling), the lowest rates were found in the GLA (8\%), followed by the NLR (22\%), and the MSP (27\%). Amongst car commuters, those in the MSP were the most dissatisfied. The majority of this subset $(58 \%)$ reported being unsatisfied with their commute. This was in contrast to the findings in both European regions, where the majority of car commuters were found to be satisfied with their commutes (NLR: 79\%; GLA: 71\%).

Interestingly, when exploring the missing data in the samples, it is found that the great majority of respondents who did not report their commuting satisfaction never commuted by car. In the GLA none of the respondents who failed to report their commuting preferences commuted by private car. In the NLR and MSP only 3 and 5 of the excluded individuals, respectively, reported commuting by car.

The link between satisfaction with commuting, and general satisfaction with life (i.e., subjective well-being), was also explored. While there was a general positive trend between these two types of satisfaction, the correlation was not particularly high ( $\tau=0.16$ with the 5-point Likert commuting satisfaction scale; $\tau=0.13$ with the binary commuting satisfaction).

In terms of gender, the descriptive statistics show that within the three samples there are not particularly large differences between the genders. In the NLR and the GLA women were slightly more likely to report being satisfied with their commute when compared to their male counterparts (NLR: $84 \%$ vs. $78 \%$; GLA: $73 \%$ vs. $70 \%$ ). In the MSP men were more satisfied than women, and the differences were slightly larger. Only $35 \%$ of women reported being satisfied with their commute, compared to $44 \%$ men. Given these descriptive results it seems that gender is more likely to be a significant factor in the MSP.

\subsubsection{Binary logistic regression results: City specific estimations}

The main results of the GLM estimations for the GLA, MSP, and NLR can be found in Table 7, Table 8 and Table 9, respectively. As explained in Section 3.4, the target variable in these models is commuting satisfaction. Descriptive statistics of the sample can be found in Table 6 .

Generally speaking, lower ACT is significantly associated with being satisfied with commuting. As commuting time increases, the odds of being satisfied decrease. Furthermore, actively commuting is positively associated with greater satisfaction. As expected, those reporting that their commuting negatively impacted other areas of their lives are more likely to be unsatisfied. Finally, greater subjective wellbeing is also associated with greater commuting satisfaction. The impact of accessibility and personal 
demographics was much more limited. Commuting preferences (i.e., ICT and MCT) were found to significantly impact commuting satisfaction in all of the case study regions, but the manner in which this occurred varied.

Table 6. Descriptive statistics of the sample used in the GLM estimations (means)

\begin{tabular}{|c|c|c|c|c|}
\hline & GLA & MSP & NLR & Total \\
\hline \multicolumn{5}{|l|}{ Dependent variable } \\
\hline Satisfaction with commute $(1 / 0)$ & 0.71 & 0.40 & 0.82 & 0.69 \\
\hline \multicolumn{5}{|l|}{ Travel times (10 minute intervals) } \\
\hline Actual commuting time (ACT) & 3.71 & 3.49 & 2.67 & 3.15 \\
\hline Ideal commuting time (ICT) & 2.22 & 2.26 & 1.93 & 2.09 \\
\hline Maximum willingness to commute (MCT) & 5.28 & 5.81 & 4.31 & 4.93 \\
\hline \multicolumn{5}{|l|}{ Modal choice } \\
\hline Always active $(1 / 0)$ & 0.08 & 0.25 & 0.22 & 0.19 \\
\hline Never car (mix) $(1 / 0)$ & 0.42 & 0.38 & 0.12 & 0.26 \\
\hline Always car $(1 / 0)$ & 0.18 & 0.21 & 0.43 & 0.31 \\
\hline Other combination (mix) $(1 / 0)$ & 0.32 & 0.16 & 0.24 & 0.24 \\
\hline \multicolumn{5}{|l|}{ Potential job accessibility (normalized) } \\
\hline ACT-based accessibility & 0.40 & 0.27 & 0.26 & 0.30 \\
\hline ICT-based accessibility & 0.07 & 0.07 & 0.08 & 0.07 \\
\hline MCT-based accessibility & 0.64 & 0.56 & 0.46 & 0.54 \\
\hline \multicolumn{5}{|l|}{ Transport difficulties } \\
\hline Negative commuting impacts $(1 / 0)$ & 0.40 & 0.25 & 0.11 & 0.22 \\
\hline Car ownership (1/0) & 0.77 & 0.60 & 0.90 & 0.79 \\
\hline \multicolumn{5}{|l|}{ Personal characteristics } \\
\hline Satisfaction with life scale (SWLS) & 19.9 & 23.2 & 25.9 & 23.6 \\
\hline Woman $(1 / 0)$ & 0.53 & 0.50 & 0.53 & 0.52 \\
\hline Age & 44.3 & 41.8 & 47.6 & 45.3 \\
\hline Education - More than high school $(1 / 0)$ & 0.49 & 0.25 & 0.53 & 0.45 \\
\hline Household size & 2.64 & 3.33 & 2.64 & 2.81 \\
\hline
\end{tabular}

In the NLR, having a larger maximum willingness to commute (i.e., MCT) was shown to increase the odds of being satisfied $(\beta=0.17 *)$. Additionally, being able to achieve ICT had a very strong association $(\beta=0.81 * *)$ with commuting satisfaction, but the ICT, in of itself, was not significant. That is, having a higher ICT did not make it more likely to report current commuting satisfaction. In the GLA, by contrast, increases in the ICT $(\beta=0.27 *)$ were significantly associated with increased satisfaction. In the MSP, the ICT and the MCT were not found to be significant, despite the direction of the relationships being as expected. However, reporting a low dissonance between your ACT and ICT (i.e., achieving your ICT) was strongly associated with satisfaction $(\beta=0.71 * *)$. Additionally, the negative association of increases in ACT was strongest in the $\operatorname{NLR}\left(\beta_{\mathrm{GLA}}=-0.41 * * * ; \beta_{\mathrm{MSP}}=-0.25 * * * ; \beta_{\mathrm{NLR}}=-0.65 * * *\right)$. 
Table 7. Associations with commute satisfaction (GLA)

\begin{tabular}{lrrrr}
\hline Commute Satisfaction & Coefficient $^{\text {a }}$ & SE & z-value & $\operatorname{Pr}(>|\mathbf{z}|)$ \\
\hline Actual commuting time (ACT) & $-0.41^{* * *}$ & 0.06 & -6.74 & 0.001 \\
Ideal commuting time (ICT) & $0.27^{* *}$ & 0.09 & 2.92 & 0.004 \\
\hline Always active (1/0) & $3.84^{*}$ & 1.65 & 2.32 & 0.02 \\
\hline Log ICT-based accessibility & $0.24^{\bullet}$ & 0.14 & 1.71 & 0.09 \\
\hline Negative commuting impacts & $-1.07^{* * *}$ & 0.20 & -5.28 & $<0.001$ \\
\hline Age & $0.56^{*}$ & 0.23 & 2.47 & 0.01 \\
Age & $-0.01^{*}$ & 0.005 & -2.30 & 0.02 \\
\hline SWLS & $0.14^{*}$ & 0.07 & 2.13 & 0.03 \\
\hline Interaction- ACT: Always active & $-1.17^{*}$ & 0.52 & -2.23 & 0.03 \\
Interaction- Age: Age & & 0.00003 & 2.07 & 0.04 \\
\hline AIC & $0.00007^{*}$ & 696 & &
\end{tabular}

${ }^{a}$ Note: ${ }^{* *} \mathrm{p}<0.001,{ }^{* *} \mathrm{p}<0.01,{ }^{*} \mathrm{p}<0.05, \bullet \mathrm{p}<0.1$

Table 8. Associations with commute satisfaction (MSP)

\begin{tabular}{lccrr}
\hline Commute Satisfaction & Coefficient & SE & z-value & $\operatorname{Pr}(>|\mathbf{z}|)$ \\
\hline Actual commuting time (ACT) & $-0.25^{* * *}$ & 0.07 & -3.71 & $<0.001$ \\
ACT $\leq$ ICT & $0.71^{* *}$ & 0.24 & 3.05 & 0.002 \\
\hline Always active (1/0) & $1.23^{*}$ & 0.57 & 2.14 & 0.03 \\
Always car (1/0) & $-0.76^{*}$ & 0.35 & -2.18 & 0.03 \\
Never car (mix) (1/0) & $-0.84^{*}$ & 0.34 & -2.50 & 0.01 \\
\hline Log ICT-based accessibility & $0.18^{*}$ & 0.10 & 1.81 & 0.07 \\
\hline Negative commuting impacts & $-0.74^{* *}$ & 0.28 & -2.66 & 0.008 \\
\hline SWLS & $0.25^{* * *}$ & 0.07 & 3.81 & $<0.001$ \\
\hline Interaction- ACT: Always active & $0.68^{* *}$ & 0.24 & -2.77 & 0.006 \\
\hline AIC & 601 & & & \\
\hline
\end{tabular}

Table 9. Associations with commute satisfaction (NLR)

\section{Commute Satisfaction}

Actual commuting time (ACT)

Maximum willingness to commute (MCT)

\begin{tabular}{lrrrr} 
Commute Satisfaction & Coefficient & SE & z-value & $\operatorname{Pr}(>|\mathbf{z}|)$ \\
Actual commuting time (ACT) & $-0.65^{* * *}$ & 0.10 & -6.84 & $<0.001$ \\
$\begin{array}{l}\text { Maximum willingness to commute } \\
\text { (MCT) }\end{array}$ & $0.17^{*}$ & 0.08 & 2.25 & 0.02 \\
ACT $\leq$ ICT & & & & 0.002 \\
\hline Always active (1/0) & $0.81^{* *}$ & 0.26 & 3.16 & 0.02 \\
Always car (1/0) & $1.00^{*}$ & 0.43 & 2.32 & 0.008 \\
\hline Negative commuting impacts & $-0.54^{* *}$ & 0.20 & -2.67 & $<0.001$ \\
\hline Age & $-1.10^{* * *}$ & 0.24 & -4.61 & 0.07 \\
\hline SWLS & $0.02 \bullet$ & 0.009 & 1.78 & $<0.001$ \\
\hline AIC & $-0.25^{* * *}$ & 0.06 & & \\
\hline
\end{tabular}


Taken together, these results seem to point to the different experienced realities and preferences in the case study regions. There is a clear indication that the respondents in the Netherlands appear to be much more averse to longer commuting times than their counterparts in London and São Paulo. Increasing commuting times is strongly negatively associated with satisfaction, and as discussed earlier, the NLR is also the only case study region where higher MCT is associated with a greater likelihood of being satisfied with commuting. This is in line with the descriptive results presented in Section 4.1. Respondents in the NLR have shorter commutes than those in the GLA or MSP, prefer even shorter commutes, and report lower tolerance for potential increases in their commute duration. In contrast, in the MSP, respondents report a willingness to commute even further despite being generally dissatisfied with their commute (only $40 \%$ report being satisfied), and having average commutes above 30 minutes (refer to Table 6). It would appear that higher ACT is a less significant predictor on its own as a result of living in a large mega city where there is a general expectation of long commuting times. In the GLA, among the tested commuting preference variables (i.e., ICT, MCT, ACT $\leq$ ICT), having higher ICT was the only significant predictor of satisfaction. This is in line with the accessibility results which showed that relying on the ICT to estimate job accessibility significantly reduced the measured accessibility, while increases in accessibility to account for MCT were less impactful (refer to Figure 5).

In terms of mode choice, and its impact on commuting satisfaction, a positive association of active commuting was found in all three case studies, but with different intensities. The positive association was lowest in the NLR $(\beta=1.00 *)$, followed by the MSP $(\beta=1.23 *)$ and then the GLA $(\beta=3.84 *)$, where it was extremely strong. Furthermore, in the MSP and the GLA, the interaction between ACT and active travel was also significant, i.e., commuting actively resulted in a diminishing impact of ACT on satisfaction $\left(\beta_{\mathrm{GLA}}=-1.17 * * ; \beta_{\mathrm{MSP}}=-0.68 * *\right)$. In the NLR, although commuting actively was positively associated with satisfaction, it did not have a significant interaction with ACT. This is interesting, and could be the result of the bicycle being considered a conventional travel mode to a greater extent than in the other case study regions. While the cause for this is not further explored here, it is relevant to note that despite active commuting mitigating the negative impacts of longer commutes on satisfaction in the GLA and the MSP, this is unlikely to be related to the infrastructure or environmental quality. Cycling infrastructure is generally of higher quality in the Netherlands, and it has been found that cyclists in the MSP are more exposed to pollutants while commuting when compared to cyclists in the GLA and Rotterdam, in the NLR (Brand et al., 2019).

Related to this, commuting by car was negatively associated with commute satisfaction in the NLR $(\beta=-0.54 * *)$ and the MSP $(\beta=-0.76 *)$. However, in the MSP, mixed commuting (i.e., respondents who reported commuting by PT to varying degrees but who never used the car) had an even greater negative association with satisfaction $(\beta=-0.84 *)$. In the GLA, the impact of commuting by non-active modes, be it car or PT, was not found to be significant.

In terms of subjective well-being, as expected, being generally satisfied with life is positively associated with higher odds of also being satisfied with commuting. However, the intensity of this effect was not overwhelming. It was found to be highest in the $\operatorname{NLR}(\beta=0.25 * * *)$, and the MSP $(\beta=0.25 * * *)$. The lowest association was found in the GLA $(\beta=0.14 *)$. This lends further credence to the fact that when assessing subjective well-being, satisfaction with commuting is unlikely to play a large role. However, as expected, those who reported that their commuting impacted other aspects of their lives were much more likely to report being unsatisfied with commuting $\left(\beta_{\mathrm{GLA}}=-1.07 * * * ; \beta_{\mathrm{MSP}}=-0.74 * * ; \beta_{\mathrm{NLR}}\right.$ $=-1.10 * * *)$. Similarly to the findings regarding the duration of the trips, this effect was strongest in the NLR, followed by the GLA. The lowest impact was found in the MSP.

Finally, increases in the zonal potential accessibility to jobs were found to have limited impacts on commuting satisfaction. Although no associations could be found in the NLR, the log of the ICT-based accessibility was found to be positively associated to greater satisfaction in the GLA and the MSP ( $\beta_{\text {GLA }}$ 
$=0.24 \bullet ; \beta_{\mathrm{MSP}}=0.18 \bullet$ ). Similarly, the socio-demographic profiles of respondents did not result in particularly strong findings. Increases in the age were found to have a small positive effect in the NLR ( $\beta$ $=0.02 \bullet)$. In the GLA both the age $(\beta=-0.56 *)$, and the age-squared $(\beta=-0.01 * *)$ terms were found to be significant, as well as their interaction $(\beta=0.000 *)$. This points to a small lessening of the effect as the age increases.

No significant results were found in terms of gender, education, or other household variables such as car ownership.

\section{$5 \quad$ Discussion and conclusions}

This paper examined relationships between commuting preferences, satisfaction with travel, general well-being and potential job accessibility in three distinct case study regions: the Randstad region of the Netherlands (NLR), the Greater London Area (GLA) and the municipality of Sáo Paulo (MSP). Potential job accessibility by PT was estimated using distance decay functions based on survey data where respondents reported their actual (ACT) and ideal (ICT) commuting times, as well as their maximum willingness to commute (MCT). This allowed us to disentangle the influence of preferences and constraints in the estimation of potential job accessibility.

In all three metropolitan regions, most respondents reported their ICT to be between 10 and 20 minutes, with only a few stating a desire to commute more than 30 minutes. This result is consistent with the findings from Redmond and Mokhtarian (2001) for ideal commuting times in the United States. The majority of the sample in each of the cases also reported current ACT exceeding their ICT. This was highest in the GLA, where $\approx 70 \%$ were unable to achieve their ICT. This is particularly relevant because ideal and maximum commuting preferences have a very large impact on the volume and spatial distribution of accessible jobs. Job accessibility based on ideal commuting preferences significantly decreases total measured accessibility (60 to 100 percent), with those living in the lowest accessibility zones being impacted the most. MCT based job accessibility, in turn, increases the measured accessibility (50 to 85 percent), in a generally linear pattern for all three cases. The significant reduction in accessibility under the ICT-based scenario, and the high level of dissonance between ICT and ACT for a majority of respondents, highlight that the current spatial-infrastructural constellation in these cities does not facilitate commuting options in-line with the preferences of residents. In fact, the estimated accessibility values for zones with the highest ICT-based accessibility to jobs, are comparable to middling accessibility levels under the ACT scenario in all three cases. Measuring ICT-based accessibility could therefore provide policy makers with a way to set accessibility improvement targets, or benchmark the existing accessibility of a region for different transport modes.

ICT and MCT were also found to impact the odds of being satisfied with commuting. However, the way in which these preferences manifested themselves in each of the regions varied. The analysis of commuting satisfaction reflects the transport, land use, and cultural differences between the GLA, MSP, and NLR. However, similar results allow us to generalize some of the findings. In particular, a strong positive association between commuting actively and commute satisfaction was found in all three case study regions. Interestingly, this result was found to be lowest in the NLR, despite tending to have higher quality active infrastructure (e.g., cycling lanes). It can be argued that a possible reason for this is that the penetration of bicycles is such that it results in an increased likelihood of commuting by bike despite this not being the particular preference of a respondent. In contrast, in the GLA and the MSP, active commuters, and cycling commuters in particular, are more likely to be commuting in this manner due to a strong preference for the mode. This would be in line with existing research where liking one's commute mode has been found to be associated with higher commuting satisfaction (Handy \& Thig- 
pen, 2019), and with the argument that the modal impact on commuting satisfaction has less to do with the characteristics of the modes themselves, and is instead much more related to whether the preferred mode is used (De Vos, 2019). This argument is further reinforced when considering that, although increases in ACT were found to be negatively associated to satisfaction in all of the regions, this finding was somewhat mitigated by actively commuting in the MSP and the GLA. This was not the case in the NLR, where an interaction between ACT and active commuting was not found.

The impact of accessibility on commuting satisfaction was less than anticipated, despite the accessibility of residential zones being important for residential location choices, and as a result, a driver of land use and demographic changes in cities (e.g., Smith et al., 2020). Results show that increases in the zonal potential accessibility to jobs have only limited impacts on satisfaction. The log of the desired accessibility was found to be only weakly positively associated to greater satisfaction in the GLA and the MSP, while no impact could be found in the NLR. In addition to the models presented in the previous sections, models without the travel variables (i.e., ICT, ACT, MCT) were tested and these had very little explanatory power and significance levels. This is a strong indication that in terms of reported satisfaction, personal mobility is of much higher importance than zonal accessibility. In the literature, several papers found associations between job accessibility and trip generation (e.g., Cordera, Coppola, Dell'Olio, \& Ibeas, 2016) and job accessibility and vehicle miles traveled (VMT) (e.g., Ewing \& Cervero, 2010). In this paper we find that the underlying psychology of travelers, expressed in satisfaction or dissatisfaction with the commuting trip, is not strongly related to potential job accessibility, which effectively combines the proximity to jobs and the travel time needed to reach those jobs. It is not surprising, however, that individual factors are more indicative of personal satisfaction than zonal potential accessibility measures. Having said this, further research is needed on this front.

Future research should be directed to further understand the relationship between accessibility, travel satisfaction, and well-being. With the ever-growing list of studies measuring accessibility to different types of opportunities in different contexts, the question of how to understand and value accessibility and (marginal) accessibility increases needs to become much more central in the literature. For instance, the value of accessibility and of how it is associated to well-being and satisfaction may be better understood through a sufficientarian lens. That is, that there is a "sufficient" level of accessibility to guarantee continued well-being, and that the importance lies in being able to reach this level. Once this threshold is reached the value of marginal increases in accessibility stop being as valuable to well-being, and more specifically to satisfaction with travel. Likewise, increased accessibility that remains below a "sufficient" level is also unlikely to highly impact satisfaction. More comprehensive job accessibility measures could also be explored further. Commuting satisfaction is likely to be more strongly related to the overall experienced daily travel impedance (including costs and comfort of traveling) rather than to travel time alone, as was included in the accessibility analysis in this paper. Finally, we are lacking knowledge on the underlying mechanisms of the ideal commuting patterns for different commuter groups (e.g., high- and low-skilled workers) and the role of the spatial-infrastructure constellations as an enabler or barrier for workers to achieve their commuting preferences.

\section{Acknowledgements}

This work was carried out under the framework of the ASTRID (Accessibility, Social justice and Transport emission Impacts of transit-oriented Development) project that was jointly funded by NWO (Netherlands; project number: 485-14-038), the ESRC (UK; grant number ES/N011481/1), and FAPESP (Brazil; grant number: 2015/50128-9). JP Pritchard was a Zuckerman STEM Leadership Research Fellow at Technion, and conducted the data collection and parts of the analysis as a researcher at the University of Twente. 


\section{References}

Brand, V., Kumar, P., Damascena, A. S., Pritchard, J. P., Geurs, K., \& Andrade, M. d. F. (2019). Impact of route choice and period of the day on cyclists' exposure to black carbon in London, Rotterdam and São Paulo. Journal of Transport Geography, 76, 153-165. https://doi.10.1016/j.jtrangeo.2019.03.007

Cerin, E., Leslie, E., du Toit, L., Owen, N., \& Frank, L. D. (2007). Destinations that matter: Associations with walking for transport. Health \& Place, 13(3), 713-724. https://doi.10.1016/ j.healthplace.2006.11.002

Chaloux, N., Boisjoly, G., Grisé, E., El-Geneidy, A., \& Levinson, D. (2019). I only get some satisfaction: Introducing satisfaction into measures of accessibility. Transportation Research Part F: Traffic Psychology and Behavior, 62, 833-843. https://doi.10.1016/j.trf.2019.03.008

Chatterjee, K., Chng, S., Clark, B., Davis, A., De Vos, J., Ettema, D., ... Reardon, L. (2020). Commuting and wellbeing: A critical overview of the literature with implications for policy and future research. Transport Reviews, 40(1), 5-34. https://doi.10.1080/01441647.2019.1649317

Choo, S., Collantes, G. O., \& Mokhtarian, P. (2005). Wanting to travel, more or less: Exploring the determinants of the deficit and surfeit of personal travel. Transportation, 32(2), 135-164. https:// doi.10.1007/s11116-004-2219-8

Cordera, R., Coppola, P., Dell'Olio, L., \& Ibeas, Á. (2016). Is accessibility relevant in trip generation? Modelling the interaction between trip generation and accessibility taking into account spatial effects. Transportation, 44, 1577-1603. https://doi.10.1007/s11116-016-9715-5

Cui, M., \& Levinson, D. (2019). Primal and dual access. Geographical Analysis, 52(3), 452-474. https:// doi.10.1111/gean.12220

De Vos, J. (2019). Satisfaction-induced travel behavior. Transportation Research Part F: Traffic Psychology and Behavior, 63, 12-21. https://doi.10.1016/j.trf.2019.03.001

De Vos, J., \& Witlox, F. (2016). Do people live in urban neighborhoods because they do not like to travel? Analyzing an alternative residential self-selection hypothesis. Travel Behavior and Society, 4, 29-39. https://doi.10.1016/j.tbs.2015.12.002

DfT. (2018a). Average number of trips, miles and time spent travelling by trip purpose (Table nts0403). London: Department for Transport. Retrieved from https://www.gov.uk/ government/statisticaldata-sets/nts04-purpose-of-trips

DfT. (2018b). Time taken to travel to work by region of workplace (Table tsgb0110). London: Department for Transport. Retrieved from https://www.gov.uk/government/statistical -data-sets/tsgb01-modalcomparisons

Diener, E. E. (1985, feb). The satisfaction with life scale. Journal of Personality Assessment, 49(1), 71-75. https://doi.10.1207/s15327752jpa4901_13

Diener, E. E. (2006). Understanding scores on the satisfaction with life scale. Urbana-Champaign, IL: University of Illinois.

Ewing, R., \& Cervero, R. (2010). Travel and the built environment: A meta-analysis. Journal of the American Planning Association, 76(3), 265-294. https://doi.10.1080/01944361003766766

García-López, M. Á., \& Moreno-Monroy, A. I. (2016). Income segregation and urban spatial structure: Evidence from Brazil. (Working paper No. 2016/08.) Caracas: CAF Development Bank of Latin America.

Gelman, A., \& Hill, J. (2007). Data analysis using regression and multilevel/hierarchical models. Cambridge, UK: Cambridge University Press.

Geurs, K., \& Ritsema van Eck, J. (2001). Accessibility measures: Review and applications (RIVM report 408505 006). Bilthoven, the Netherlands: RIVM - National Institute of Public Health and the 
Environment.

Geurs, K., \& van Wee, B. (2004). Accessibility evaluation of land-use and transport strategies: Review and research directions. Journal of Transport Geography, 12(2), 127-140. http://doi.10.1016/j.jtrangeo.2003.10.005

Handy, S., \& Thigpen, C. (2019). Commute quality and its implications for commute satisfaction: Exploring the role of mode, location, and other factors. Travel Behavior and Society, 16, 241-248. https://doi. 10.1016/j.tbs.2018.03.001

Hansen, W. G. (1959). How accessibility shapes land use. Journal of the American Institute of Planners, 25(2), 73-76. https;/doi.10.1080/01944365908978307

Humagain, P., \& Singleton, P. A. (2020). Investigating travel time satisfaction and actual versus ideal commute times: A path analysis approach. Journal of Transport \& Health, 16, 100829. https// doi.10.1016/j.jth.2020.100829

Jain, J., \& Lyons, G. (2008). The gift of travel time. Journal of Transport Geography, 16(2), 81-89. https://doi.10.1016/j.jtrangeo.2007.05.001

Lancée, S., Veenhoven, R., \& Burger, M. (2017). Mood during commute in the Netherlands: What way of travel feels best for what kind of people? Transportation Research Part A: Policy and Practice, 104, 195-208. https://doi.10.1016/j.tra.2017.04.025

Mokhtarian, P. (2019). Subjective well-being and travel: Retrospect and prospect. Transportation, 46, 493513. https://doi.10.1007/s11116-018-9935-y

Morris, E. A., \& Guerra, E. (2015). Are we there yet? Trip duration and mood during travel. Transportation Research Part F: Traffic Psychology and Behavior, 33, 38-47. https://doi.10.1016/ j.trf.2015.06.003

Morris, E. A., \& Zhou, Y. (2018). Are long commutes short on benefits? Commute duration and various manifestations of well-being. Travel Behavior and Society, 11, 101-110. https://doi.10.1016/j. tbs.2018.02.001

Morris, J., Dumble, P., \& Wigan, M. (1979). Accessibility indicators for transport planning. Transportation Research Part A: General, 13(2), 91-109. https://doi.10.1016/0191-2607(79)90012-8

Moya-Gómez, B., \& García-Palomares, J. C. (2017). The impacts of congestion on automobile accessibility. What happens in large European cities? Journal of Transport Geography, 62, 148-159. https:// doi.10.1016/j.jtrangeo.2017.05.014

ONS. (2017). The national statistics socio-economic classification (NS-SEC). Retrieved from https:// perma.cc/RL6N-H4CN

Pritchard, J. P., Tomasiello, D., Giannotti, M., \& Geurs, K. (2019a). An international comparison of equity in accessibility to jobs: London, São Paulo and the Randstad. Findings, February, 1-9. https:// doi.10.32866/7412

Pritchard, J. P., Tomasiello, D., Giannotti, M., \& Geurs, K. (2019b). Potential impacts of bike-and-ride on job accessibility and spatial equity in São Paulo, Brazil. Transportation Research Part A: Policy and Practice, 121, 386-400. https://doi.10.1016/j.tra.2019.01.022

R Core Team. (2020). R: A language and environment for statistical computing [Computer software]. Vienna: The R Project for Statistical Computing. Retrieved from https://www.R-project.org/

Redmond, L., \& Mokhtarian, P. (2001). The positive utility of the commute: Modeling ideal commute time and relative desired commute amount. Transportation, 28(2), 179-205. https:// doi.10.1023/A:1010366321778

Ribeiro, A. G., Baquero, O. S., de Almeida, S. L., de Freitas, C. U., Cardoso, M. R. A., \& Nardocci, A. C. (2019). Influence of vehicular traffic density on hospital admissions due to respiratory tract cancer in the city of São Paulo, Brazil. Cadernos de Saúde Pública, 35(1), e00128518. https:// doi.10.1590/0102-311X00128518 
Shaw, F. A., Malokin, A., Mokhtarian, P., \& Circella, G. (2019). Who doesn't mind waiting? Examining the relationships between waiting attitudes and person and travel related attributes. Transportation, 48, 395-429. https://doi.10.1007/s11116-019-10054-2

Smith, D., Shen, Y., Barros, J., Zhong, C., Batty, M., \& Giannotti, M. (2020). A compact city for the wealthy? Employment accessibility inequalities between occupational classes in the London metropolitan region 2011. Journal of Transport Geography, 86(June), 102767. https://doi.10.1016/j.jtrangeo.2020.102767

Stichting LISA. (2014). Landelijk InformatieSysteem van Arbeidsplaatsen (LISA). Retrieved from https://www.lisa.nl/home

St-Louis, E., Manaugh, K., van Lierop, D., \& El-Geneidy, A. (2014). The happy commuter: A comparison of commuter satisfaction across modes. Transportation Research Part F: Traffic Psychology and Behavior, 26, 160-170. https://doi.10.1016/j.trf.2014.07.004

Stępniak, M., Pritchard, J. P., Geurs, K., \& Goliszek, S. (2019). The impact of temporal resolution on public transport accessibility measurement: Review and case study in Poland. Journal of Transport Geography, 75, 8-24. htttps://doi.10.1016/j.jtrangeo.2019.01.007

van Ham, M. (2002). Urban form and job access: Disparate realities in the Randstad. In Job access, workplace mobility, and occupational achievement (pp. 13-34). Utrecht, the Netherlands: Eburon Publishers.

van Wee, B., \& Geurs, K. (2016). The role of accessibility in urban and transport planning. In M. Bliemer, C. Mulley, \& C. Moutou (Eds.), Handbook on transport and urban planning in the developed world (pp. 53-66). Cheltenham, UK: Edward Elgar Publishing. https://doi.10.4337/9781783471 393.00010

Ye, R., De Vos, J., \& Ma, L. (2020). Analyzing the association of dissonance between actual and ideal commute time and commute satisfaction. Transportation Research Part A: Policy and Practice, 132, 47-60. https://doi.10.1016/j.tra.2019.10.011

Yee, T. (2015). Vector generalized linear and additive models: With an implementation. New York: Springer. https://doi.10.1007/978-1-4939-2818-7

Zhu, J., \& Fan, Y. (2018). Commute happiness in Xi'an, China: Effects of commute mode, duration, and frequency. Travel Behavior and Society, 11, 43-51. https:/doi.10.1016/j.tbs.2018.01.001 